\title{
PENGALAMAN KOMUNIKASI PENULIS TUNANETRA (STUDI FENOMENOLOGI DI PERPUSTAKAAN BALAI PENERBITAN BRAILLE ABIYOSO BANDUNG)
}

\author{
Junaidin', Irham² \\ 1,2 Program Studi IImu Komunikasi STISIP Mbojo Bima \\ Korespondensi: Jalan Pierre Tendean No. 28 Kel. Mande Kec. Mpunda Kota Bima, NTB \\ Surel: junaidinbima86@gmail.com
}

INFO ARTIKEL

\section{Sejarah Artikel:}

Diterima: 07/01/2021

Direvisi: 18/01/2021

Dipublikasikan:

30/01/2021

e-ISSN: 2721-0995

p-ISSN: 2721-9046

Kata Kunci:

Baca Tulis Tunanetra

Pengalaman Komunikasi

Keywords:

Blind Reading and Writing

Communication Experience

\section{ABSTRAK Pengalaman Komunikasi Penulis Tunanetra} (Studi Fenomenologi di Perpustakaan Balai Penerbitan Braille Abiyoso Bandung). Penelitian ini dimaksudkan untuk mengetahui dan memahami pengalaman komunikasi penulis tunanetra dalam dunia baca tulis. Pengalaman komunikasi pembaca dan penulis tunanetra merupakan proses komunikasi tentang kegiatan membaca dan menulis yang mendalam baik sedang membaca buku braille maupun menulis karya inspiratif. Kesadaran ini lahir dari kemauan sekaligus kemampuan dalam mengamalkan kegiatan membaca dan menulis sebagai pengalaman fisik sekaligus psikis. Cara khusus yang dilakukan peneliti untuk mengungkap temuan tentang pengalaman komunikasi penulis tunanetra adalah menggunakan metode kualitatif khusus pendekatan fenomenologi. Melalui beberapa teknik pengumpulan data, yaitu pengamatan, wawancara mendalam, dan dokumentasi. Teknik itu digunakan sebagai alat untuk mengupas dan mengkaji pengalaman komunikasi para pembaca dan penulis tunanetra. Temuan yang didapatkan peneliti dari hasil penelitian tentang pengalaman komunikasi tunanetra dalam dunia baca tulis yakni pengalaman komunikasi psikofisik, yakni gabungan antara pengalaman fisik dan psikis dalam kegiatan membaca dan menulis di kalangan tunanetra.

A B S TR A CT The Communication Experience of Blind Writers (Phenomenology Study at the Library of Braille Publishing House Abiyoso Bandung). The aim of this study is to know and to understand the communication experience of blind writers in the aspect of reading and writing activity. The communication experience of blind readers and writers is a process about deep reading and writing activities, whether they read braille books or write some inspirational works. This awareness resulted from the willingness as well as the ability to practice of reading and writing either as a physical or as a psychological experience. The method used in this study is qualitative method with a phenomenological approach. Data collection used several techniques such as observation, depth interviews and documentation. The techniques were suitable for exploring and examining the communication experiences of blind readers and writers. This study found that the experiences among blind people communications in reading 
and writing activities are actually combinations of physical and psychological experiences.

\section{PENDAHULUAN}

Pembahasan topik ini berawal dari perjalanan dan pengamatan di sebuah gedung Perpustakaan Balai Penerbitan Braille Indonesia (BPBI) Abiyoso Kota Bandung. Sejumlah tunanetra mengaktifkan jari-jari tangan, sambil menggeser ke kiri dan ke kanan bagian titiktitik kertas yang menonjol ke permukaan. Mereka membaca berbagai karya seperti kitab suci, buku-buku agama, novel karya Habiburrahman El-Shirazi seperti Ayat-Ayat Cinta dan Ketika Cinta Bertasbih, novel pop karya Iwan Setiawan yaitu 9 Summers 10 Autums: dari Kota Apel ke The Big Apple.

Buku-buku nonfiksi juga hadir sebagai bacaan penambah wawasan dan pembentuk keyakinan berekspresi para tunanetra dalam membaca beberapa cerita lucu (anekdot), buku ilmu pengetahuan alam, buku ilmu sosial dan ilmu-ilmu lainya. Selain deretan karya-karya yang digeluti dan dibaca dari berbagai bidang ilmu, para tunanetra juga telah menulis beberapa puisi, buku pribadi seperti Bintang-Bintang di Balik Awan, Kartini, Tunanetra dan Organisasi Ketunanetraan.

Sejumlah hasil karya tunanetra merupakan penyaluran bakat alami dan disadari sebagai pengalaman membaca dan menulis yang telah dirasakan setiap individu. Artinya para tunanetra sendiri yang mengalami penyelaman ide, kesenangan, keharuan, fantasi, perenungan spiritual melalui bahan bacaan tanpa campur tangan pihak luar. Berdasarkan pandangan yang bersifat interpretatif atau fenomenologis, tunanetra merupakan subjek nyata dalam kehidupannya sebagai pembaca sekaligus penulis.

Para tunanetra adalah aktor kehidupan yang memiliki kemauan, tekad, dan impian secara subjektif melalui kegiatan baca tulis di lingkungannya sehingga asumsi kecacatan atau kekurangan indra visual seharusnya tidak lagi dijadikan sebagai pesan mutlak dan anggapan umum untuk mendiskreditkan kalangan tertentu. Namun, keterbatasannya itu harus lebih dianggap sebuah anugerah dalam penyaluran bakat manusia sebagai ciptaan Tuhan.

Pandangan subjektif dari para tunanetra diperlukan untuk menetralkan pandangan orang awam terhadap tunanetra. Biasanya orang-orang suka menyimpulkan secara umum kemampuan baca tulis tunanetra, tanpa terlebih dahulu menggali makna-makna khusus yang kemungkinan bisa menghasilkan makna baru berdasarkan apa yang dirasakan dan dialami tunanetra sendiri. Oleh karena itu, diperlukan keterbukaan dan kesadaran dalam mengkaji kemampuan baca tulis tunanetra yang tidak jauh berbeda dengan kalangan awas (bukan tunanetra).

\section{TINJAUAN PUSTAKA}

Penelitian yang dilakukan oleh Rahman Agus Priyana (2012) yang berjudul Strategi untuk Meningkatkan Kemampuan Baca Tulis Al-Qur'an Braille bagi Tunanetra Muslim 
di TPA LB Yaketunis menggunakan strategi direct instruction (hafalan dan tanya jawab), strategi interaktif (diskusi dan tanya jawab), strategi mandiri (metode pemberian tugas). Ketiga strategi tersebut merupakan langkah-langkah untuk mencapai kemampuan baca tulis tunanetra.

Penelitian berikutnya, dilakukan oleh Sari Rudiyati (2010) berjudul Pembelajaran Membaca dan Menulis Braille Permulaan pada Anak Tunanetra yaitu membahas mengenai pemberian kompensasi keterbatasan visual dengan melatih indra-indra taktual dan memodifikasi cara dan alat baca tulis. Artinya kedua penelitian tersebut masih menitikberatkan pada metode belajar saja, seakan-akan subjek yang diteliti adalah orangorang yang selamanya harus dibantu oleh pihak nontunanetra dengan alasan memiliki kekurangan indera visual, tanpa memikirkan kekuatan dan kepekaan indra lain yang samasama memiliki kemampuan dalam berkegiatan khususnya kegiatan baca tulis tunanetra.

Sejumlah kajian bisa digunakan untuk mengungkapkan fenomena baca tulis tunanetra dalam rangka menemukan makna dan konsep-konsep populer berdasarkan pengalamanpengalaman yang dialami para tunanetra. Salah satu yang menarik adalah gabungan antara kajian psikofisik dan ilmu komunikasi. Bila diperhatikan berdasarkan cabang ilmu yang lebih luas, ilmu psikologi tentu memiliki kedudukan dan pengaruh cukup kuat terhadap perkembangan ilmu yang lain, misalnya dalam psikologi komunikasi. Kedudukan ilmu komunikasi memiliki makna untuk mengungkap suatu kehidupan yang khas ditinjau dari proses interaksi, segala penyampaian energi, gelombang suara, tanda di antara tempat, sistem atau organisme (Rakhmat, 2015: 4).

Sementara itu, kajian psikologi menyebut komunikasi adalah penyampaian energi dari alat-alat indra ke otak pada peristiwa pengolahan informasi dan penerimaan pesan. Jika ditelusuri dari kegiatan baca tulis tunanetra, secara fisik timbulan huruf braille diproses kemudian disampaikan kepada syaraf pusat melalui proses perabaan atau sentuhan. Dalam teori Gibson, hal itu disebut persepsi langsung melalui alat indra terlebih dahulu, kemudian menangkap pesan dari luar menuju ke syaraf pusat atau memori yang dapat menghasilkan sebuah makna.

Pengalaman komunikasi yang dirasakan para tunanetra tentang baca tulis merupakan proses berpikir untuk memahami isi dalam kajian tentang membaca dan menulis sebagai sebuah aktivitas yang penting dalam kehidupan agar membudaya. Pada sisi lain juga diperlukan kolaborasi dengan berbagai pendekatan cabang ilmu yang beragam. Hasil penelitian akademisi diharapkan dapat dijadikan dasar untuk mendorong pemerintah membuat kebijakan yang lebih berpihak dalam pengadaan bahan bacaan secara merata. Secara teoretis, kajian ini juga dapat memberikan gambaran mengenai teori fenomenologi dan teori tentang persepsi langsung dari Gibson melalui kolaborasi dengan bidang ilmu komunikasi, sehingga muncul pertanyaan bagaimana pengalaman komunikasi tunanetra dalam dunia baca tulis.

\section{METODE}

Tujuan penelitian ini secara umum untuk menemukan dan memahami pengalaman 
komunikasi para pembaca dan penulis tunanetra, sekaligus untuk memahami secara mendalam pengalaman subjektif para tunanetra melalui masalah dan kondisi alamiah. Atas dasar itulah digunakan pendekatan kualitatif dengan metode fenomenologi yang diasosiasikan dengan keinginan seseorang untuk menelaah makna, konteks, dan pendekatan holistik terhadap suatu fenomena (Mulyana \& Solatun, 2008: 5-6).

Sebuah pendekatan dalam metode fenomenologi merupakan langkah awal untuk memurnikan objek dari pengalaman dan prasangka awal (Kuswarno, 2009: 49) sehingga dalam praktiknya peneliti lebih mengesampingkan dugaan-dugaan dan pengambilan kesimpulan terlebih dahulu mengenai pengalaman yang diungkap oleh informan (narasumber). Menurut Cresswell, (2014: viii) pendekatan fenomenologi menyarankan seorang peneliti untuk menunda beberapa kesimpulan awal untuk menjaga kemurnian dari pengalaman para narasumber. Penundaan ini biasa disebut dengan epoche. Konsep epoche menjadi pusat bagi seorang peneliti ketika harus mengurungkan niat dalam pengambilan kesimpulan terlebih dahulu tentang apa yang dialami oleh para informan atau tunanetra terhadap fenomena yang terjadi.

Penentuan informan penelitian dilakukan secara purposive sesuai dengan syarat dan kebutuhan penelitian. Ada beberapa pertimbangan dalam melakukan pemilihan sejumlah informan, yaitu:

1. Narasumber atau informant dalam penelitian ini adalah tunanetra low vision, buta total, dan paham baca tulis.

2. Narasumber kunci atau key informant yang dipilih merupakan tunanetra yang biasa baca tulis dan memiliki karya tulis.

3. Narasumber kunci dipilih berdasarkan kesediaan dan kemampuan dalam mengungkapkan pengalaman baca tulis dan memahami dunia baca tulis.

Sejumlah pencatatan dan identifikasi dilakukan seperti menelaah penelitian-penelitian sebelumnya mengenai pemilihan subjek penelitian. Selain itu, diperlukan karakteristik, perwakilan, dan kesesuaian fenomena yang dialami oleh para informan atau narasumber yang terpilih. Oleh karena itu, dalam memilih dan menentukan sumber informasi diperlukan berbagai upaya pendekatan dan seleksi secara bertahap dari setiap pertemuan yang berlangsung di tempat penelitian.

Dalam menentukan inti dari beberapa pertemuan, diperlukan diskusi dengan melihat latar belakang, hobi, dan minat yang digeluti, seperti jenis bacaan yang disukai dan berapa banyak karya yang telah ditulis dalam kegiatan baca tulis. Kemudian disesuaikan dengan kebutuhan penelitian. Tentu dalam mendekati narasumber kunci seperti tunanetra, perlu kejelian untuk memahami berbagai sisi berdasarkan karakter yang dimiliki setiap narasumber dengan cara sering bertemu dan bercakap-cakap secara intensif. Sebagian dari tunanetra cukup peka dalam mengingat, mengenal suara, mengidentifikasi gaya bahasa, dan mengetahui sentuhan dengan orang yang diajak berkomunikasi.

Teknik pengumpulan data dilakukan dengan cara pengamatan, wawancara mendalam, dan dokumentasi. Pada proses pengamatan, peneliti mengamati fenomena yang dialami 
oleh para tunanetra dalam kegiatan membaca dan menulis. Kemudian membuat catatan lapangan ke dalam sebuah buku catatan untuk mendeskripsikan sejumlah informasi yang telah dikumpulkan untuk dianalisis lebih lanjut. Lalu, dalam proses wawancara mendalam sengaja tidak dibuat panduan wawancara terstruktur kecuali dari hasil pertanyaan dan perbincangan secara alami yang direkam menggunakan alat perekam handphone dan panduan observasi awal.

Jika teknik yang dilakukan untuk mendapatkan setiap jawaban yang diberikan oleh informan kurang memuaskan, peneliti melakukan pengecekan kembali sejumlah uraian lalu bertanya lagi pada hari-hari lain secara terus menerus sesuai kebutuhan penelitian dan memeriksa setiap dokumen dan sumber-sumber lainya. Dokumen diperiksa secara fisik dan diteliti sebelum data digunakan berdasarkan konfirmasi dengan sejumlah tunanetra.

\section{HASIL DAN PEMBAHASAN}

\section{Hasil Penelitian}

Hasil penelitian yang dipaparkan dalam bagian ini berupa deskripsi hasil pengamatan dan ungkapan hasil wawancara. Berikut adalah deskripsi dan narasi selengkapnya sebagai gambaran dalam pelaksanaan penelitian ini.

la berjalan melangkah menuju ruangan perpustakaan sambil menunggu acara yang akan segera dimulai. Seorang tunanetra bernama Sulas sudah terlebih dahulu mengisi meja baca yang terletak di samping rak buku braille. Kemudian ia mengambil beberapa majalah dengan penuh perhatian. Jari-jarinya mengikuti setiap timbulan aksara braille yang sedikit dipahami ketika diraba. Sentuhannya cukup santai, menindih beberapa huruf dan kalimat yang berkaitan dengan tema acara bedah buku yang akan diselenggarakan di ruangan sederhana dan sejuk itu. Tangannya mulai satu per satu menyentuh titik kasar. Ada rasa yang membentuk pemahaman yang tersambung melalui kekuatan rabaan. la meraba bagianbagian dari huruf braille yang menyatu dengan kertas melalui kekuatan organ sensorik yang kemudian ditampung ke dalam memori.

Dalam wawancara mendalam, ia menyatakan:

"Baca tulis rata-rata huruf braille, pola dan titik-titik seperti parutan, kekuatan rabaan menjadi hal utama. Kalau setiap pola dan titik sudah terbaca biasanya dari organ sensorik akan memberikan pemahaman dan tersimpan ke dalam memori."

Dalam pengamatan selanjutnya terdeskripsi sebagai berikut:

Seorang tunanetra menggerakkan reglet, baik saat menulis maupun menemukan titik-titik pada sebuah kombinasi dari pola, simbol, kata, kalimat gambar, grafik dengan panjang dan jenis bahan bacaan yang berbeda-beda. Proses fisik sudah dialami oleh para tunanetra melalui kegiatan teknis baca tulis dari beberapa buku fiksi dan nonfiksi yang telah disediakan oleh perpustakaan dengan mengandalkan kekuatan rabaan. la pun menyatakan pendapatnya sebagai berikut:

"Meraba itu ya seperti membiasakan diri aja agar jari-jari tangan lebih peka. Syaraf motorik dan sensorik tidak bisa dipisahkan mas, kegiatan ini juga memerlukan konsentrasi." 
Kekuatan rabaan yang dialami oleh tunanetra melalui proses motorik sensorik merupakan pengalaman fisik sekaligus psikis yang merupakan bagian dari pengalaman komunikasi para pembaca dan penulis tunanetra.

\section{Pembahasan}

Hal pertama yang dialami oleh tunanetra adalah rasa ingin tahu dan motif apa yang membuat para tunanetra ingin melakukan kegiatan dan pengalaman komunikasi para tunanetra dalam kegiatan membaca dan menulis. Temuan tentang pengalaman komunikasi dalam dunia baca tulis tunanetra berdasarkan hasil penelitian yakni pengalaman komunikasi psikofisik, yaitu gabungan dari hasil kekuatan rabaan saat menyentuh timbulan-timbulan braille dan menulis dengan reglet yang terhubung pada syaraf pusat yang selanjutnya menjadi kumpulan konsep dalam kepala sehingga membutuhkan kemampuan motorik sekaligus kemampuan sensorik.

Pengalaman fisik berkaitan dengan proses perabaan melalui kegiatan motorik. Kekuatan perabaan menimbulkan rasa pada syaraf motorik-sensorik yang berhubungan dengan persepsi tunanetra untuk membentuk konsep dalam pikirannya. Hal ini bertalian dengan persepsi langsung yang dikemukakan oleh Gibson, yaitu terjadi kegiatan fisik melalui pengalaman indrawi (rabaan) menuju ke syaraf pusat. Artinya pengalaman indrawi (rabaan) harus terpenuhi terlebih dahulu ketika proses motorik (jari-jari) dalam mendapatkan pengetahuan saat membaca dan menulis serta memperoleh makna di dalamnya. Saat membaca, tunanetra memerlukan tindakan yang dipicu oleh proses berpikir dan diekspresikan oleh tampilan. Proses ini memerlukan keterampilan motorik umum, keterampilan persepsi rabaan, keterampilan persepsi suara, kecepatan bahasa, formasi konsep, dan keterpaduan antara sensori.

Ketika sedang menulis, para tunanetra melakukan tindakan yang dipicu oleh proses berpikir dan diekspresikan oleh tampilan. Proses ini memerlukan intelektual dalam mengenal ukuran, bentuk, dan orientasi huruf. Intelektual kontrol motorik berupa aktivitas memegang dan menuliskan huruf. Intelektual koordinasi tangan berupa rabaan. Intelektual memori untuk mempelajari dan mengingat bentuk huruf. Tunanetra dibekali dengan berbagai pengalaman yang meningkatkan kemampuan baca tulis, pengalaman yang mendukung kesadaran fonemik, korespondensi huruf, bunyi, konsep tentang tulisan cetak, dan pemahaman melalui kemampuan baca tulis.

Sejumlah pengalaman tersebut merupakan kenyataan sekaligus kesadaran yang bersifat subjektif yang berhubungan dengan gerak fisik dan bisa dijelaskan juga dalam bidang neurologi. Ketika berpikir tentang baca tulis tunanetra, yang akan muncul adalah sebuah gambaran sejumlah gerak fisik, jari-jari tangan pada aksara-aksara braille melalui syaraf motorik-sensorik untuk mendapatkan pemahaman dalam pikiran. Para tunanetra memahami baca tulis sesuai dengan pengalaman pikiran yang dialaminya. Inilah yang disebut Husserl sebagai intensionalitas (intentionality), yakni kesadaran selalu merupakan kesadaran akan sesuatu. Kemudian menganalisis struktur-struktur dasar kesadaran secara 
detail, seperti persepsi, penilaian, tindakan, ruang, waktu, tubuh, keberadaan orang lain, dan sebagainya.

Pengalaman komunikasi psikofisik mewakili pengalaman umum tunanetra saat melakukan kegiatan baca tulis dengan kekuatan rabaan dan kekuatan pikiran. Keduanya memiliki hubungan yang erat untuk membangun makna baca tulis. Setelah pengalaman terlihat secara keseluruhan dari proses fisik, kemudian proses psikis. Proses fisik yang dialami juga membutuhkan sensitivitas jari untuk mendukung kesadaran fonemik, korespondensi huruf, bunyi, konsep tentang tulisan cetak dan pemahaman seperti membaca dan menulis buku. Jika jari-jari atau kulit kurang peka, otomatis kekuataan rabaan atau sensitivitas jarinya susah bekerja dengan baik.

\section{SIMPULAN}

Berdasarkan hasil penelitian dan pembahasan, terdapat pengalaman komunikasi yang dialami oleh tunanetra yaitu pengalaman komunikasi psikofisik. Pengalaman ini merupakan gabungan antara proses fisik dan proses psikis dalam kegiatan membaca dan menulis. Pengalaman komunikasi psikofisik dalam dunia baca tulis tunanetra membuat mereka mengenal dunia.

Terdapat beberapa saran yang dapat disampaikan melalui karya tulis ini. Pertama, diharapkan kepada para pengambil kebijakan agar membantu dalam proses pengadaan bahan bacaan untuk mendukung semangat membaca dan menulis para tunanetra. Kedua, selain mengenalkan kajian tentang pengalaman komunikasi penulis tunanetra dalam dunia baca tulis secara tekstual, diharapkan ada penelitian pembanding yang dapat mengembangkan pengalaman baca tulis secara umum dan kontekstual, seperti membaca keadaan dan lingkungan sekitar, khususnya bagi kalangan tunanetra.

\section{DAFTAR RUJUKAN}

Agus Priyana. (2012).Strategi untuk Meningkatkan Kemampuan Baca Tulis Al-Qur'an Braille bagi Tunanetra Muslim di TPA LB Yaketunis. Skripsi Universitas Islam Negeri Sunan Kalijaga Yogyakarta

Creswell, John W. (2014). Penelitian Kualitatif dan Desain Riset. Jogjakarta: Pustaka Pelajar Kuswarno, Engkus. (2009). Metodologi Penelitian Komunikasi Fenomenologi: Konsepsi, Pedoman dan Contoh Penelitianya. Bandung: Widya Padjadjaran.

Mulyana, Deddy \& Solatun (2008). Metode Penelitian Komunikasi. Bandung: Rosda Karya Rakhmat, Jalaluddin. (2015). Psikologi Komunikasi. Bandung: Rosda Karya

Rudiyati, Sari. (2010). Pembelajaran Membaca dan Menulis Braille Permulaan pada Anak Tunanetra. JASSI ANAKKU (Jurnal Asesmen dan Intervensi Anak Berkebutuhan Khusus), 9(1), 57-65. 